\title{
A Review of the Usable Food Delivery Apps
}

\author{
${ }^{1}$ Hafiz U R Rahman \\ Department of computer science \\ Federal Urdu University of Arts, Science \&Technology, \\ Islamabad, Pakistan
}

\author{
${ }^{3}$ Muhammad Abrar \\ Bacha Khan University Charsadda \\ Pakistan
}

\author{
${ }^{2}$ Mahmood Ashraf \\ Department of computer science \\ Federal Urdu University of Arts, Science \&Technology, \\ Islamabad, Pakistan \\ ${ }^{4}$ Abid Mehmood \\ Department of Management Information Systems \\ King Faisal University Al-Ahsa, Saudi Arabia
}

\begin{abstract}
Objective: This paper presents the overall background of food delivery applications and procedure of ordering of food through food delivery applications. Today period is assumed, the world of information technology. Now a day, people are familiar to use computers, mobiles and mobile applications.

Methods/ statistical Analysis: This study focused on all the available food ordering systems whether manual or, digital and grouped into 14 different categories. Then every category was explained in detail. Later some commonly used applications were evaluated. Then the technology used for these applications are highlighted.

Findings The study concluded that the use of digital application in the food ordering systems are increasing and become more popular in the customers.

Application/ Improvements However but there are still some usability issues in the current available food delivery applications. There is need to developed the mobile applications that purely applied the usability rules and guidelines.
\end{abstract}

Keywords:- Online food ordering system, mobile apps, food delivery apps Introduction

\section{INTRODUCTION}

Online food ordering and delivery is the process in which order for the food is placed through internet and delivered to the customer to the specified place. Food delivery Apps, online food ordering systems is basically designed for those People that don't have time to go to restaurant. As the say, money is not money but time is money [1].

These systems impressively simplify the ordering process for both customers and restaurants owner, this is the main advantage of online food ordering or delivery system. In past manual food ordering system will be used. In this system customers have to go to the restaurant and waiter takes order from the customer and writes down in the paper [2].

In this system each and every type of record is stored on the paper. Then the waiter sends the order to the kitchen for the further processing [1] [2]. Then Personal Digital Assistant technology was used. Personal digital assistant is a portable device like smartphone every waiter should have the PDA and take order form customers. To cover the limitation of PDA multi touch technology come to market, where the user has the authority to perform and control different type of operations at a time on multi touch screen. To cover the limitation of all the previous food ordering systems, mobile food ordering system been developed. This system automates all food ordering process. In the recent time of information technology people are familiarized to use computer, mobile and mobile Apps. On the other hand the use of mobile application and their development is also growing fast area of information technology. Mobile Application has not only impact the Smart phone users but also play a vital role in our daily business life [3]. The first mobile which is come to market is so simple, that just have, clock, alarm, and simple calculator.

Basically, mobile Apps consists a set of instruction that runs on Smart phones and perform a specific task. Developer built mobile application for different purposes [2]. Mobile applications are Easy to use, User friendly, Inexpensive, Convenient to carry, Powerful development framework, simply downloadable, run on most of the mobile phone. There are a number of Apps which are pre-installed in Smart phones and others Apps users can easily download, installed in smartphone [2].

In the past, people used mobile phone just for receiving call, messaging and doing simple calculations etc. Now a day, Mobile Phones are Used Commonly due to different functionalities i.e. user can used for calling, used for messaging, used for browsing, used for chatting, used for social network communication, and users can also use for audio, video, games etc. Mobile food ordering and food delivery is one of most popular area of mobile application development [3].

The online food delivery application is impressively good for those people that don't have time to go the restaurant. Anyone who have smart phone they can easily order for the food from anywhere and they can receive food at her/her home. Payment can be either on delivery or by credit card [3].

\section{LITERATURE REVIEW}

Previous And Some Existing Food Order system

\section{A. Conventional Paper Based System}

Paper based system is one of the most widely used food ordering system in the past. In this system customers have to go to the restaurant and waiter takes order from the 
customer and writes down in the paper. In this system each and every type of record is stored on the paper. Then the waiter sends the order to the kitchen for the further processing. The main drawback of this system is wastage of time and money [4] [5].

\section{B. Self-Service Restaurant}

To cover the limitation of manual restaurant system self-service restaurant system introduced. There are a lot of drawback of manual system like, wastage of money and time. In manual system a lot of effort required for small amount of change [2].

In the proposed system every customer goes to the restaurant and place order in the service counter. customer have to take decision in advance, and customer either select item form the catalog which is presented in the form of poster and placing normally behind the order counter [2] [4].

\section{Self-Serviced Food Ordering}

The proposed system is the integration of web technology with hotel management system. The integrated system is applicable to any size of the hotel chain environment. This system increases the efficiency of the hotel which saves the customer time. It provides real time feedback to the customers [6].

$\mathrm{K}$ means and apriori algorithm are used in the proposed system. The prosed system has the usable interface. This system provides real time customer feedback and provides a user friendly ordering environment. The system will to reduce the cost of labor and also simplify the order process [6].

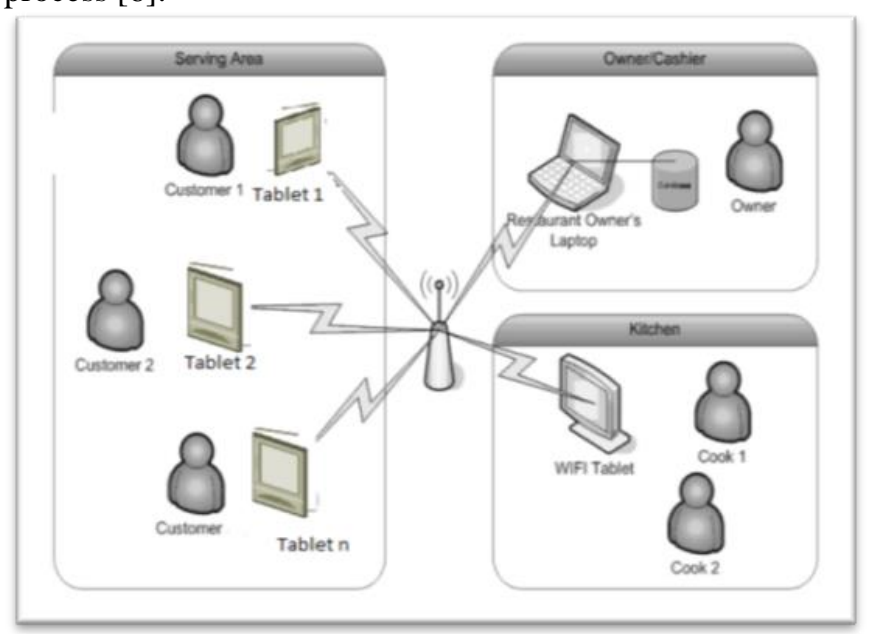

Fig. 1 Architecture Diagram

\section{Personal Digital Assistant}

Personal digital assistant is a portable device like smartphone every waiter should have the PDA and take order form customers. According author, the personal digital assistant and smartphones are used by the limited number of people in the past. Still due to potential, sales and the user of smartphones are increasing day by day [7].. The modern market of smartphone, mobile offers a variety of choice and lifestyle. Some of the phones are small and silky; many people like and use them, due to ease of carrying. The PDA are used by number of people, therefor if a customer with infected disease uses a PDA other customer may be affected by the same type of disease [7].

\section{E. Multi Touch Technology}

Multi touch technology is the advance version of the existing technology, where the user has the authority to perform and control different type of operations at a time on the multi touch screen. And multiple users can interact to the display at a time. But there are some limitations of this technology, the touch screen which is available in the market are capacitive and resistive type which is much costly.

Limitation of capacitive screen that is more costly and have short life time. It may be affected in the dusty and dirty environment. The main aim of the proposed system is to increase the efficiency of the food ordering system, and minimize the human error and provide satisfactory service to the customers [8].

\section{F. Food Ordering System with Zigbee Technology}

The proposed system is based on the ZigBee technology. It is special kind of technology which has many features like secure transmission of the data, reliability, low cost, long battery life etc. According to the network functionality the zigbee is divided into two categories. Full Function Device (FFD) and Reduced Function Device (RFD). Full function detection device which act as a network coordinator that communicates with other devices [9].

The Reduced Function Device is used for the communication with the Full Function Device. In the Entire network of the zigbee technology there is only one Full Function device used. It receives data from the RFD and then stores it in database. At the end the network system server will send the order to kitchen for further processing. In the proposed system there is no need of waiter to take order from the customers. The menu will be displayed automatically on the system attached to the table where customer can touch the screen and view the detail about the food item and can directly order for the food without intervening [9][14].
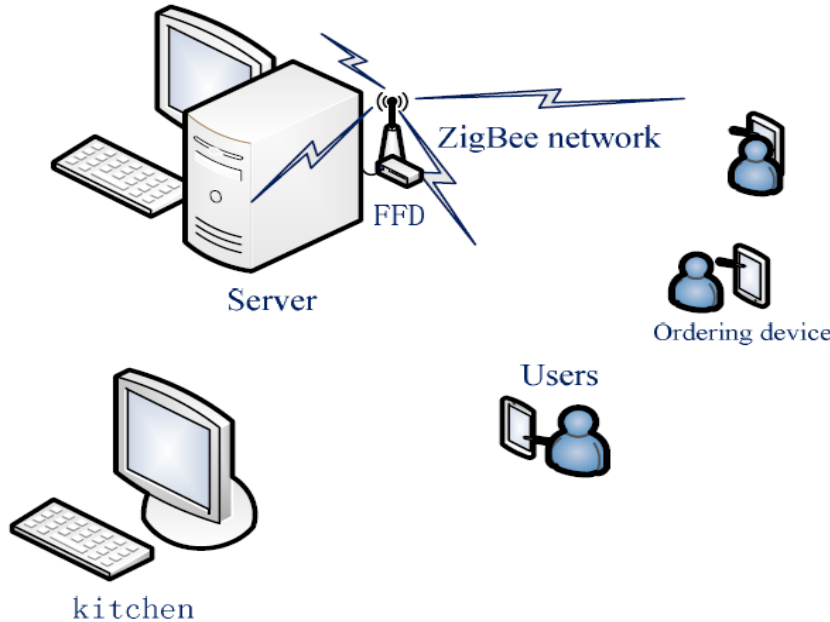

Fig. 3 Architecture of ordering system 


\section{G. Customizable Wireless Food Ordering System}

Customizable wireless food ordering systems consist of three main areas which are, serving area, restaurant manager working desk and the kitchen [10]. There are four main components of CWFOS.

- Apps on the smart phone which is used for customer order

- The web based App on the laptop for the manager of the restaurants.

- The database in which manager store over all information

- The wireless infrastructure which support network communication.

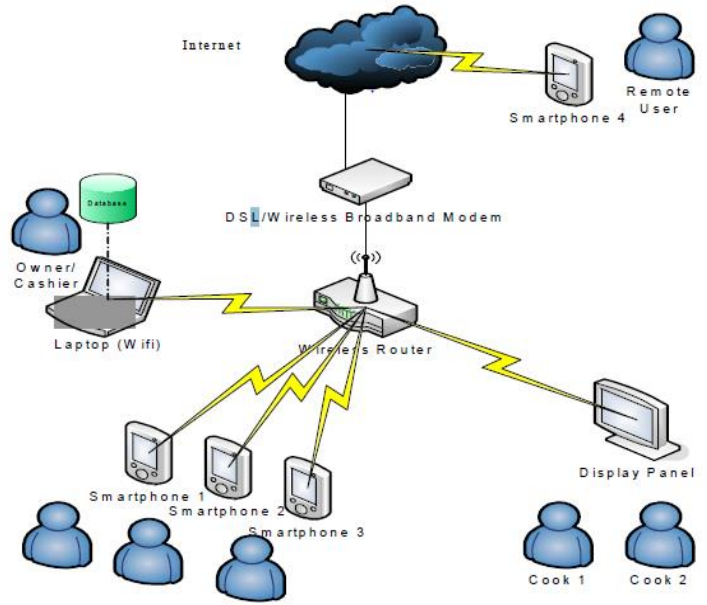

Fig. 4 System Architecture

CWFOS is the updated system where the system over all environments set wirelessly and restaurant manage the overall system easily. In this system smart phone have been integrated, due to real time communication, between restaurant owner, and different type user of the system [9][10].

\section{H. Wireless Food Ordering System Using K Mean and} Apriori Algorithm

In this paper the author proposed a new system for food ordering which is based on $\mathrm{k}$ - means and apriori algorithm. By using proposed system the customers place order for the food by using android touch pad. This system covers main three areas which are, serving area, cashier table and the kitchen. There will be android touch based screen on each table. The customer can see the menu list of food item and can easily place order just by clicking the item [11]

Then menu of the proposed system is prearranged an eye-catching way. And restaurants owner or manger can add, update and delete the menu items. The text messages are sent time to time to the customer about the discounts and suitable deals. The proposed system has two modules which is, Customer module and admin module. The admin module will be used a number of mining methods like apriori and $\mathrm{k}$ mean algorithms, for exploration purpose [11].

\section{Mobile Food Ordering System}

Mobile food ordering system is a tool which provides food Ordering facilities by installing it in Smart Phones. It provide many useful feature to the users like map location of the nearest available hotel, detailed menus and the previous look of the order. It also provides the call facility to restaurants. The proposed system consist of two part one for admin and second for the customer. The feature which is needed for the customer is profile, order, menu, and courier. The feature which is needed for the admin section is Resto, order, menu and customer [12].

When customer book and confirmed the flight all the related information will be save in database. After booking the flight a confirmation message will be showed to the customer and to tell him that your order is placed successfully. The proposed Application was developed using Android Studio software design. The user friendly layout was designed in XML. PHP and MySQL were used in backend to process request, store and manage data. [13].

\section{Pizza Hut Digital Order system main aim is to provide} following features

- User friendly food ordering system

- Convenient system that manager easily manages the overall system

- Smart delivery system providing helping facility to improve the quality of the delivery services

customer can simply doing registration and place order to book the ticket for watching cricket in then Amman international cricket stadium [15].

The proposed system consists of two part one web Application computer and also mobile Application. The mobile Application is developed for both android and ios platform. The working procedure is like customer downloads the app and selects the food item and place order [15].

Then the order will send to forward, the manager of the restaurant is able to manage the information details and status of the order. The customer will receive the hot meal or food item for which place the order. This Application is designed for both the customer and restaurant owners. For user area they can view and menu and select different type if dishes. [15].

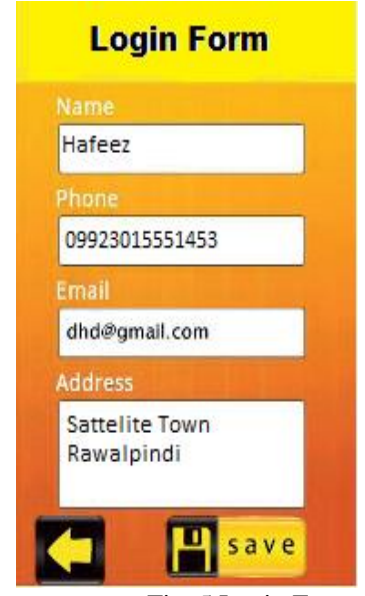

Fig. 5 Login Form

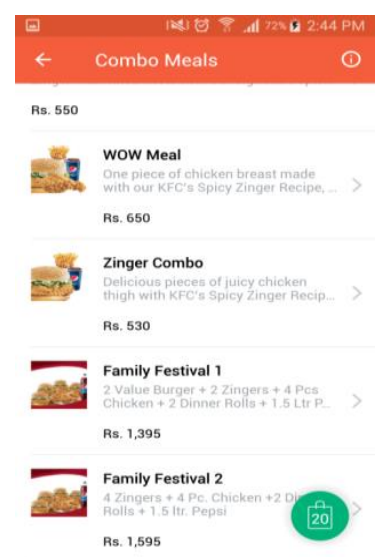

Fig. 6 Menu List 

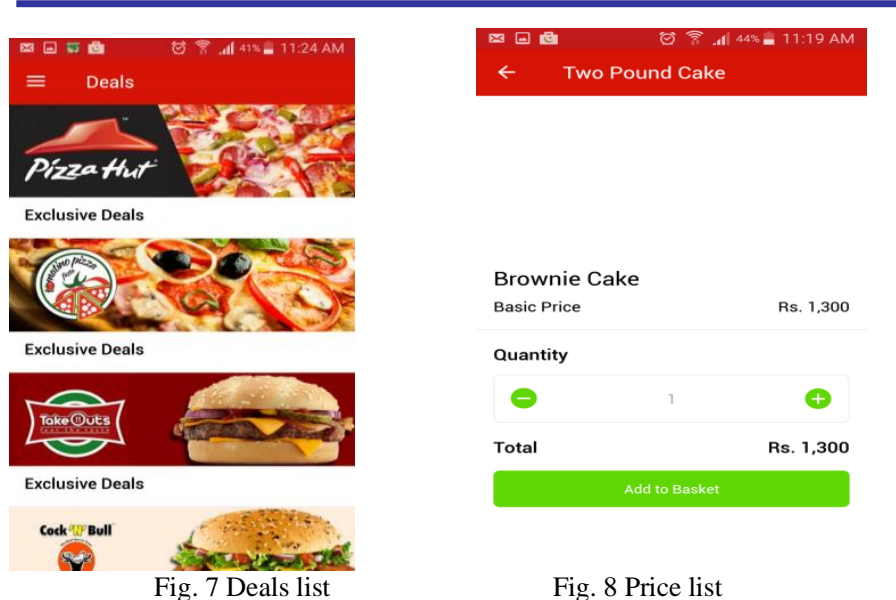

Fig. 8 Price list

\section{Mobile Bus ticketing System}

Mobile Bus Reservation system is most widely used system in the current era of information technology. The proposed system will reduce the ticket process for the customers. This system will make the life style of the customer easy, any form anywhere who have smartphone and reserve his seats. The mobile ticking system consists of four actors who communicate with the system [16].

Firstly, passenger will book the ticket, this system will allow the customer to check and search the availability of the system. This system will be available 24 hour a days and 7 days a week. Second one is the Admin who will manage the whole system. Admin can add, edit, delete, and bus route and also the whole information about destination [16].

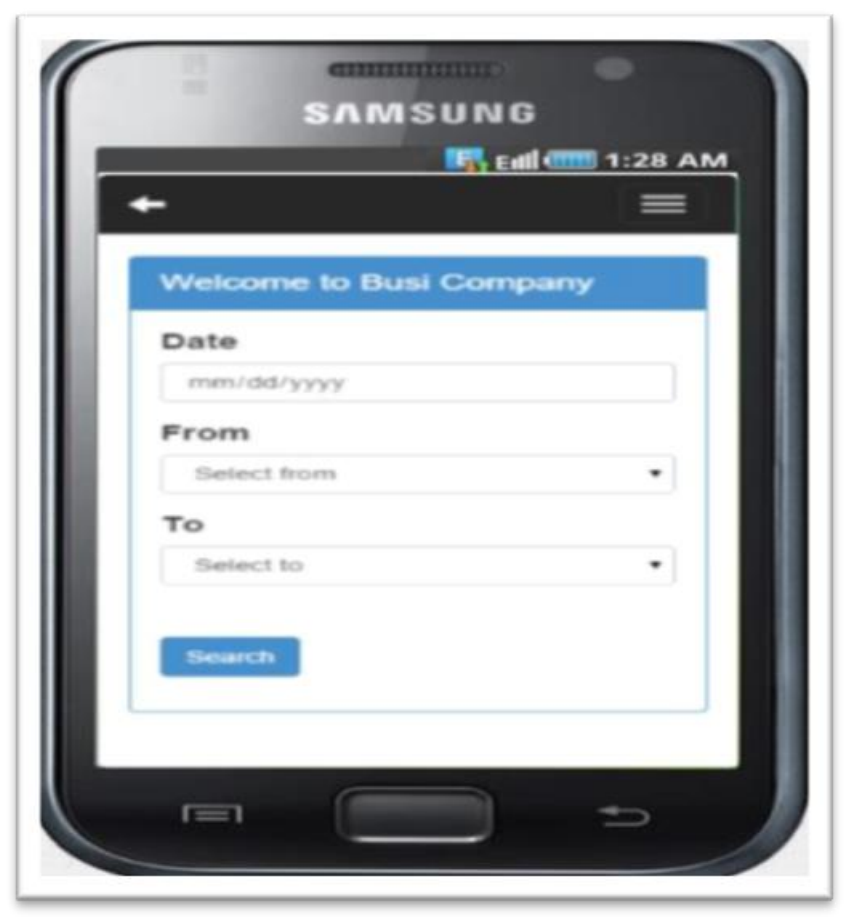

Fig. 1 booking page
N. Digital Table Booking \& Food Ordering System Using Android Application

The proposed Application simplifies the food ordering process for both customers and restaurant manager. The Application consist of many parts like Ordering menu, billing menu, restaurant table, Home deliver, advertisement etc. The App consists of two parts one for customer and one restaurant owner. On the customer side Application allow user to search the food specified food item with price, category of items. By just click on the food item, it will be added to the bosket list.The customers are allowed to change or delete the food items [17].

The detail of Available Apps and the feature that should be available in mobile Apps is given below.

A. Swiggy Food

Swiggy food is an effective and efficient food delivery application it provide various information about the food items and dishes. Through this App anyone who has smartphone or internet facility can buy food from more than thousand Restaurants across the word. www.swiggyfood.com. It offers user friendly service to the users.

\section{B. EatOye}

EatOye is free available food delivery Application. it is available. Through this App anyone who has smartphone or internet facility can buy food from more than thousand Restaurants across the word. It provides a number of the food items for customers. Www.EatOye.com. It offers user friendly Service to the users.

C. Super meal

Super meal is online food delivery service and market place particularly designed for provide online food services. It Provide efficient service. It provides information about the availability of the food, its ratting and also delivery time of the food. It also provide great role for upgrading food choices for the Customers. www.supermeal.pk.

\section{Food Panda}

Food panda is a best global mobile food delivery application which headquartered in Berlin Germany it operates in 43 countries and has 4000 partnered Restaurants. Anyone who wants to place orders then first they did registration then they can view the available restaurants details. Customer can select the food items and place the order for the food.

Food panda send confirmation message to customer for the confirmation of the order if he/she replies then order send for the further processing. Customer can received the food with in limited time and specified location (www.foodpanda.com). Below is the several screens short food panda application. 


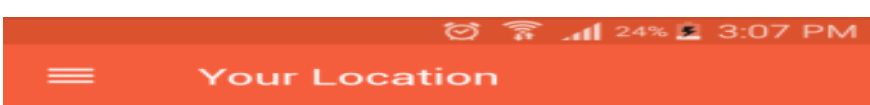

\section{Welcome! Where should} we deliver to?

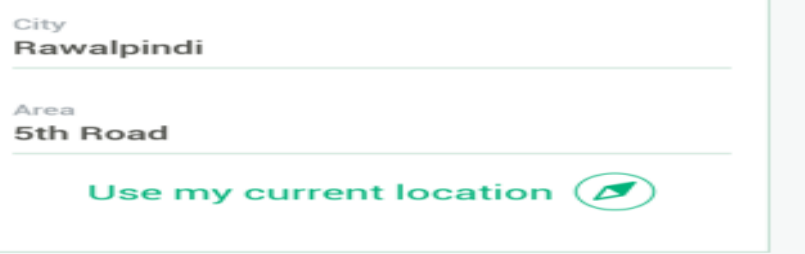

Show Restaurants

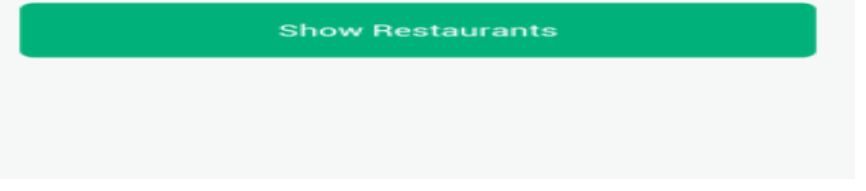

Fig. 1 Main page

According to Ricky feature which should be in food delivery application are given in the table.

\section{A. Profile restaurant}

Profile restaurant is the feature which is used to show the restaurant profiles. The admin can edit, delete, modify the

Restaurant data including the state of restaurant are Active or inactive.

\section{B. Order}

Order is the main feature that will be used to place the order for the food.

\section{Order History}

Order history feature is used to show customers order histories, which include first order and last order. D. Menu

Menu is the feature that will be used to show the list of food items and its prices.

\section{E. Courier}

Courier is the feature which is used to show the available courier list of restaurants.

\section{E. Order status}

Order status is the feature which is used to show the Status of order. Means that order has been received by restaurant, or under the processing.

\section{F. Profile setting}

Profile setting is the feature that will be used to change the Customer name, address and phone number. G. Exit

Exit is the feature that will be used to logout from the application.

\section{DEVELOPMENT TOOLS AND USED RESEARCH METHODOLOGY}

The following are the tools which were used in the development of previous proposed systems.

\section{JAVA}

Java is high level programming language, which developed by sun microsystem. It was originally designed to develop the web Application. The syntax of java language is just like c++ programming language. But it is purely object oriented programming language. Java program consist of classes and methods. The java program are interpreted by java virtual machine which almost the entire platform. The java program developments require a java software development kit, which typically include complier, interpreters, and documentation generator etc. which is used to produce a complete code [18].

\section{MYSQL}

MYSQL is Open source freely available relational database management system, which uses structure query language. SQL is structure query language which is used to add, remove, update and access the content of database. It is widely used due to its processing speed, high reliability and flexibility of use [18] [19].

\section{3. $P H P$}

PHP stand for peripheral Hypertext preprocessor, it is widely use journal purpose scripting language. It was originally developed for the development of web base application. The code of PHP is embedded with HTML hypertext markup language to create and produce dynamic webpages. It is free available programing language and run on different platform including Linux, Unix, and window operating system etc. PHP is easy to learn and easy to understand [19].

\section{USED RESEARCH METHODOLOGY}

In the above overall discussed system normally both qualitative and quantitative research methodology. User based testing is the type of qualitative research method in which users are directly participate. In this method users are requested to perform the task on the App or product, or in other way to explore it freely [20].

While using the product there behavior are observed and recorded for the purpose to identify the flaw, the error and difficulties. When user perform the tasks these things to be noted, time required to perform the task, task-completion rates and the number and type of errors, are recorded. If the flaws in the product are identified then design recommendation are proposed to improve the usability of the App [20].

User based testing is the type of qualitative research method in which user are directly participate. In this method user are requested to perform the task on the App or software product. When user perform the tasks these things to be noted, time required to perform the task, task-completion rates and the number and type of errors, are recorded. [21].

Heuristic evaluation is the type of research method, in which a small group of evaluator are presented to interface and asked to judge the product or the App follows usability principles. It is most commonly used usability evaluation method, in which both expert and non-expert user participate. Then main advantage of usability evaluation is the ability to 
don a lot of work with short period of time with limited resources [20][21].

\section{Usability Heuristics:}

A. Visibility of the system status: feedback

The system always informed the user through

B. Match between system and real world:

The used language and pictures etc. should be familiar to user.

C. User control and freedom:

User should be exit from the system and provide the facility of redo and undo.4

D. Consistency and standard:

Follow the platform convention and user should be easily performed their task.

E. Error prevention

Try to eliminate error if error come a proper guidance message should be should to user

F. Recognition rather than recall:

Reduce the user memory capacity by making objects, action and option noticeable to user.

G Flexibility and efficiency of use:

Design the system in such a way the novice and expert user can easily performed their task.

F. Aesthetic and minimalist design: beautiful.

The design of the system should be simple and

G. Help users recognize, diagnose and recover from error:

The error message should be in simple language and clearly indicate the error and also suggest the solution.

H. Help and documentation:

It is better that system can be used without documentation. If need the provide appropriate documentation to the users [22].

\section{TABLE I. USABILITY HEURISTICS}

\begin{tabular}{|l|l|l|l|l|l|}
\hline & \multicolumn{6}{|l|}{ Nielson's Usability Heuristics } \\
\hline Apps Name & $\mathbf{1}$ & $\mathbf{2}$ & $\mathbf{3}$ & $\mathbf{4}$ & $\mathbf{5}$ \\
\hline Food panda & Yes & Yes & No & Yes & No \\
\hline Swiggy food & No & Yes & No & Yes & No \\
\hline Toss town & Yes & Yes & No & No & No \\
\hline Eatoye & Yes & No & Yes & Yes & Yes \\
& & & & & \\
\hline Super Meal & Yes & Yes & yes & Yes & No \\
\hline Food panda & Yes & Yes & No & Yes & No \\
\hline
\end{tabular}

In the above table 1 we have shown the Nielsen's ten usability guideline which mostly applicable to any web or desktop application. We have checked all the guidelines in the above listed Apps those Apps which have guideline are shown by yes and rests of them are shown by no.

\section{TABLE II. USABILITY HEURISTICS}

\begin{tabular}{|l|l|l|l|l|l|}
\hline & \multicolumn{6}{|l|}{ Nielson's Usability Heuristics } \\
\hline Apps Name & $\mathbf{6}$ & $\mathbf{7}$ & $\mathbf{8}$ & $\mathbf{9}$ & $\mathbf{1 0}$ \\
\hline Food panda & Yes & No & Yes & No & No \\
\hline Swiggy food & Yes & No & No & No & Yes \\
\hline Toss town & Yes & No & Yes & No & No \\
\hline Eatoye & No & Yes & Yes & No & No \\
& & & & & \\
\hline Super Meal & No & No & No & No & No \\
\hline
\end{tabular}

In the above table II we have shown the ten usability Guidelines which mostly applicable to any web or mobile Application. To check these usability guidelines in the above listed application we have performed a user study. Total 12 participants take parts in this user study. Both male and female took part in this user study. Majority of participant are Smartphone users, among these participants, 5 participants are mobile Application developer and remaining are normal Smartphone users. We have set some tasks, participants performed the tasks and fill the consent form in which we have asked question about the availability of the above features .Those Apps which have the above listed feature are shown by yes and the remaining is shown by no. We take the five most used food delivery application to perform the tasks, and to check the availability of these guidelines.

TABLE III. USABILITY HEURISTICS

\begin{tabular}{|c|c|c|c|c|c|c|c|}
\hline Apps name & $\begin{array}{c}\text { Profile } \\
\text { restaurant }\end{array}$ & Order & $\begin{array}{c}\text { Order } \\
\text { History }\end{array}$ & Menu & Order status & Profile setting & Exit \\
\hline Food panda & Yes & Yes & $\mathrm{No}$ & Yes & $\mathrm{No}$ & $\mathrm{No}$ & $\mathrm{No}$ \\
\hline EatOye & Yes & Yes & No & Yes & No & No & $\mathrm{No}$ \\
\hline Super meal & Yes & Yes & $\mathrm{No}$ & Yes & $\mathrm{No}$ & Yes & Yes \\
\hline Toss down & Yes & Yes & $\mathrm{No}$ & Yes & $\mathrm{No}$ & $\mathrm{No}$ & $\mathrm{No}$ \\
\hline Swiggy food & Yes & Yes & No & Yes & Yes & No & Yes \\
\hline
\end{tabular}


In Table III we have used the five famous food delivery Application Apps. According to the Rickey some feature should be in food delivery Apps. To check feature in the above listed application we have performed a user study. Total 12 participant's parts in this user study. Both male and female took part in this user study. Majority of participant are software developer, among these participant 5 participants and Mobile Application developer.

We have set some tasks, participants performed the tasks and fill the consent form in which we have asked question about the availability of the above features.

Those Apps which have the above listed feature are shown by yes and the remaining is shown by no.

\section{CONCLUSION AND FUTURE WORK}

This paper presents, all the proposed systems related to the food delivery, food ordering and food delivery applications. But in all these proposed system there are a lot of drawbacks. In conventional system waiter take order from customers and write down on the paper then send to the kitchen for further processing. To cover the limitation of conventional paper based system, personal digital assistant system, multi touch screen technology system has introduced which enabled users to use that touch screen for ordering food. Then wireless food ordering system come which also enabled, the customer to get a real-time feedback. This system changed to mobile food ordering and delivery process but there are still some limitation and usability issues. Now we are going to develop a Usable food delivery application according to the current customer needs and also to fulfill all the available usability issues in these systems.

\section{REFERENCES}

[1] HARRIS, H. K. S. D. F. (2014). Software Development Aspects of a Mobile Food Ordering System.

[2] Chavan, V., Jadhav, P., Korade, S., \& Teli, P. (2015). Implementing Customizable Online Food Ordering System Using Web Based Application. International Journal of Innovative Science, Engineering \& Technology, 2(4).

[3] Islam, R., Islam, R., \& Mazumder, T. (2010). Mobile application and its global impact. International Journal of Engineering \& Technology (IJEST), 10(6), 72-78.

[4] Bhargave, A., Jadhav, N., Joshi, A., Oke, P., \& Lahane, S. R. (2013). Digital Ordering System for Restaurant Using Android. International journal of scientific and research publications, 3(4), 1-7.

[5] Shinde, R., Thakare, P., Dhomne, N., \& Sarkar, S. (2014). Design and Implementation of Digital dining in Restaurants using Android. International Journal of Advance Research in Computer Science and Management Studies, 2(1).

[6] Patil, R. V., Kale, A., Pawar, D., \& Patil, T. (2017). Wireless Customizable Food Ordering System for a Restaurant Using Apriori and K-means Algorithm. Imperial Journal of Interdisciplinary Research, 3(4)

[7] Samsudin, N. A., Khalid, A., Kamal, S., Kohar, M., Akmal, M. F., Senin, Z., \& Ihkasan, M. N. (2011). A customizable wireless food ordering system with realtime customer feedback.

[8] Bora, P. R., \& Gupta, E. (2012). Application On Order Management System In Restaurants. International Journal of Application or Innovation in Engineering \& Management (IJAIEM), 1(2), p59-p62.

[9] Asan, N. B., Nordin, N. A., \& Shariff, Z. (2014). Zigbee-Based Smart Ordering System (SOS). International Journal of Computer Trends and Technology (IJCTT)-volume, 11.

[10] Samsudin, N. A., Khalid, A., Kamal, S., Kohar, M., Akmal, M. F. Senin, Z., \& Ihkasan, M. N. (2011). A customizable wireless food ordering system with realtime customer feedback.

[11] Patil, R. V., Kale, A., Pawar, D., \& Patil, T. (2017). Wireles Customizable Food Ordering System for a Restaurant Using Apriori and K-means Algorithm. Imperial Journal of Interdisciplinary Research, 3(4).

12] Leong, W. H. (2016). Food Ordering System Using Mobile Phone (Doctoral dissertation, UTAR)

[13] Abdullah, M. N., \& Kadhim, E. H. (2016). Airline mobile reservation development. development, 3(10), 1-3.

[14] Alfawaer, Z. M., Awni, M., \& Al-Zoubi, S. (2011). MOBILE ETICKETING RESERVATION SYSTEM FOR AMMAN INTERNATIONAL STADIUM IN JORDAN. International Journal of Academic Research, 3(1)

[15] Ye, T. (2016). Pizza Hot Digital Order and Delivery System(Doctoral dissertation, Cornell University)

[16] Ibrahim, A. K., \& Ta'a, A. B. (2015). MOBILE-BASED BUS TICKETING SYSTEM IN IRAQ. European Journal of Computer Science and Information Technology, 3(5), 42-55.

[17] Dhore, V. B., Thakar, S., Kulkarni, P., \& Thorat, R. (2014). Digital Table Booking and Food Ordering System Using Android Application. International Journal of Emerging Engineering Research and Technology, 2(7), 76-81

[18] Deitel, P., \& Deitel, H. (2011). Java How to program. Prentice Hall Press

[19] Valade, J. (2011). PHP and MySQL Web Development All-in-one Desk Reference For Dummies. John Wiley \& Sons.

[20] Bastien, J. C. (2010). Usability testing: a review of some methodological and technical aspects of the method. International journal of medical informatics, 79(4), e18-e23.

[21] Mansar, S. L., Jariwala, S., Shahzad, M., Anggraini, A., Behih, N., \& AlZeyara, A. (2012). A usability testing experiment for a localized weight loss mobile application. Procedia Technology, 5, 839-848.

[22] Gafni, R. (2009). Usability issues in mobile-wireless information systems. Issues in Informing Science \& Information Technology, 6. 